\title{
Rastros e restos de Carolina Maria de Jesus
}

Carolina Maria de Jesus' tracks and remnants

Rastros y restos de Carolina María de Jesús

\author{
Érika Cecília Soares Oliveira \\ Maria Laura Medeiros Bleinroth \\ Yasmin Maciane da Silva \\ Rayanne Caroline da Silva Amorim \\ José Cícero dos Santos Júnior \\ Willamys da Costa Melo
}

Universidade Federal de Alagoas (UFAL), Maceió, AL, Brasil.

\begin{abstract}
Resumo
As contribuições de Carolina Maria de Jesus se estendem para diferentes campos epistemológicos e práticas cotidianas. Considerando a magnitude de suas palavras, buscamos neste artigo reconstruir sua trajetória através da leitura de suas obras mais populares e, a partir disso, mergulharmos em algumas pistas que a escritora nos oferece. As pistas que trilharemos são: a fome (re)lembrada; a importância da escolarização; a escrita testemunhal; o olhar da mulher negra para a branquitude feminina e para as relações étnico-raciais e o ser negra(o) no Brasil. Como efeito da pluralidade temática localizada em seus escritos, compreendemos que seu potencial teórico nos fornece sustentação sobre diferentes eixos de subordinação mediante seu entrelaçamento transdisciplinar, evidente tanto em seus diários quanto em sua escrita ficcional.
\end{abstract}

Palavras-chave: Carolina Maria de Jesus; Saberes Subalternos; Transdisciplinaridade.

\begin{abstract}
Carolina Maria de Jesus' contributions are extended to different epistemological fields and everyday practices. Considering the magnitude of her words, in this article we try to reconstruct her trajectory through the reading of her most popular works and, from that, to dive into some clues that the writer offers us. The tracks we will follow are: the hunger remembered; the importance of schooling; the testimonial writing; the view of black women on the feminine whiteness and on the ethnic-racial relations and being black in Brazil. As an effect of the thematic plurality in her writings, we understand that her theoretical potential
\end{abstract}


provides us support on different axes of subordination through its transdisciplinary interlacing, evident in her diaries as wells as in her fictional writing.

Keywords: Carolina Maria de Jesus; Subaltern Knowings; Transdisciplinarity.

\section{Resumen}

Las contribuciones de Carolina María de Jesús se extienden hacia diferentes campos epistemológicos y prácticas cotidianas. Considerando la magnitud de sus palabras, buscamos en este artículo reconstruir su trayectoria leyendo sus obras más populares y, a partir de eso, nos sumergiremos en algunas pistas que la escritora nos ofrece. Las pistas que seguiremos son: el hambre recordado; la importancia de la escolarización; la escritura testimonial; la mirada de la mujer negra hacia la blanquitud femenina y las relaciones étnico-raciales y el ser negro(a) en Brasil. Como efecto de la pluralidade temática ubicada en sus escritos, entendemos que su potencial teórico nos brinda apoyo en diferentes ejes de subordinación a través de su entrelazamiento transdisciplinario, evidente tanto en sus diarios como en su escritura ficcional.

Palabras-clave: Carolina María de Jesús; Conocimientos Subalternos; Transdisciplinariedad.

\section{Introdução}

Gostaríamos aqui de trazer a ideia de "resto" para pensarmos a escrita de Carolina Maria de Jesus, justamente por se tratar de uma escrita que, tendo vivido nas margens, se constituiu como a "Outra" dos cânones literários. Resto, segundo Stuart Hall (2016), foi a forma como as populações indígenas e negras foram tratadas à época da expansão colonial ocidental. A noção de ocidente, para existir, precisou da construção de seu oposto, o seu Outro ou, nas palavras de Spivak (2010), o "Outro da Europa". Essas(es) Outras(os) têm tido, secularmente, suas vozes obliteradas pelas grandes narrativas, aquelas que se acreditam civilizadas, desenvolvidas e, no caso da literatura, aquelas que se autodenominam, em termos linguísticos e estéticos, cultas. Estamos aqui fazendo paralelos entre aventuras além-mar e o modo como diferentes grupos organizam suas palavras, justamente por acreditarmos que tais questões encontram-se profundamente coladas umas nas outras. Isso porque o extermínio da produção de conhecimento que dizia respeito aos povos indígenas e negros encontra, nos dias de hoje, tentativas de apagamento, desqualificação naquelas(es) que, sobreviventes, tentam abrir espaço e apresentar sua visão de mundo. Carolina Maria de Jesus, escritora mineira, escreveu diários como Quarto de despejo: diário de 
uma favelada (1960), Casa de Alvenaria: diário de uma ex-favelada (1961), Diário de Bitita (1977), e também romances, como Pedaços da Fome (1963) e tem nos ensinado a seguir seus rastros por meio de suas pegadas. Pegadas essas muitas vezes feitas em longos trajetos, pois nem sempre Carolina tinha dinheiro para pagar um transporte. Nestes anos, a partir do contexto de um Projeto de Iniciação Científica (2017-2019) intitulado "Pistas de Carolina Maria de Jesus para a intervenção psicossocial", desenvolvido no curso de Psicologia de uma Universidade Federal na região Nordeste, estivemos debruçadas(os) sobre suas principais obras, também em biografias e textos que nos fizessem entender um pouco mais a existência dessa mulher que, com dois anos de escolaridade, conseguiu colocar em palavras e em mais de cinco mil folhas tudo aquilo que ia pelo seu universo (Oliveira, no prelo; Oliveira, Bleinroth, Santos, Silva, Melo, 2018; Oliveira, 2017). Essas folhas e as reflexões nelas contidas, muitas delas tiradas de latas de lixo, poderiam aqui ser compreendidas como os "restos" de que fala Stuart Hall. A própria Carolina muitas vezes se referia como sendo ela e as(os) faveladas(os), o rebotalho da sociedade, aqueles restos que não se deseja mais, que se joga em qualquer fundo de quintal, ambiente longínquo para que as vistas embranquecidas da população não tenham que se responsabilizar pela produção de seus dejetos.

O resto de que fala Hall (2016) poderia também criar vinculações com o conceito de Outridade proposto por Grada Kilomba (2019). Outridadeteria a ver com a personificação de aspectos ruins do "eu" de sujeitos brancos direcionados aos sujeitos negros assim como "restos" têm a ver com a criação, por parte de europeus, de outros menos qualificados. De certa forma, Carolina coloca todas essas questões em seus livros. O que ela faz, com sua carga poética, é um exercício de que nos falava Frantz Fanonem Pele negra, máscaras brancas: tendo percebido que só poderia existir a partir da exploração que o olhar branco fazia de seu corpo negro, o psiquiatra martinicano abre sobre sua pele lâminas de aço para defender-se.E, com isso, uma carga poética que resgatará e atualizará as cosmovisões negras, aquilo que se produziu a despeito de ou mesmo antes de se começarem as diásporas e o atlântico ser palco de tanto sofrimento.

Nosso objetivo neste trabalho é seguir as pegadas da escritora Carolina Maria de Jesus e, ao fazê-lo, apresentar as pistas que ela nos oferece ao trilhar seu caminho. A partir da leitura de algumas de 
suas obras mais emblemáticas, vamos reconstruindo a trajetória desta mulher que ficou conhecida pela publicação de um diário no qual pôs em evidência a vida de milhares de brasileiras(os) pauperizadas(os). As pistas que serão apresentadas a seguir são: a fome (re)lembrada, a importância da escolarização, a escrita testemunhal, o olhar da mulher negra para a branquitude feminina e as relações étnico-raciais e o ser negra(o) no Brasil.

\section{Primeira pista: A fome (re)lembrada.}

A primeira pista é a "fome (re)lembrada".A priori, gostaríamos de apresentar, em síntese, o enredo de Casa de Alvenaria, trazendo o outro mundo da escritora após sair da favela do Canindé. O início da obra retrata os frutos colhidos pelo sucesso de Quarto de despejo, exibindo o quão complicada é a elaboração subjetiva de Carolina dentro da casa de alvenaria (Fernandez, 2015). O novo diário de Carolina foi publicado pouco mais de um ano em relação ao primeiro e a recepção do público nacional e internacional nem se igualava ao sucesso e impacto de divulgação da sua obra anterior, sendo vendidas apenas três mil obras de uma tiragem inicial de 10 mil exemplares (Miranda, 2013; Fernandez, 2015).

As primeiras páginas do livro contam que as pessoas começavam a falar sobre Carolina e a reconhecer por onde perambulava, antes do lançamento oficial da obra. $\mathrm{O}$ que contribuiu para esse fato foi a circulação de reportagens com o auxílio do jornalista alagoano Audálio Dantas, como podemos visualizar aqui: "ele disseme que já me viu nos jornais e nas revistas e deu-me mais lenhas" (Jesus, 1961, p. 11). Em virtude desse reconhecimento, a escritora almejava sair dessa vida tão difícil: "a vida de miséria vai acabar - falei sorrindo" (Jesus, 1961, p. 15). Em contraste com sua primeira obra, na qual a escritora dizia: "Fui buscar agua. Fiz o café. Avisei as crianças que não tinha pão" (Jesus, 1960, p. 9), esta obra manifesta o alívio por ter alimento na mesa: "que bom saber que temos o que comer. Parece até que a minha vida transformou-se. Da fome para a fartura" (Jesus, 1961, p. 18). A fome ainda assombra e, ao mesmo tempo, é promessa de tornar-se pura lembrança: "O João gostou da comida e gritou: - Viva a Dona Carolina! Sorri. Êle [sic] olhou-me por longo tempo e disse-me: - Por estes dias temos comida e a senhora não precisa chorar" (Jesus, 1961, p. 15). Não muito tempo depois, a fome havia se distanciado da casa de Carolina (Miranda, 2013) e logo 
começou a surgir felicidade no barraco no Canindé, que tinha alimento na mesa todos os dias: "Êles estão alegres porque comeram" (Jesus, 1961, p. 16).

Em concordância com Souza (2016), o alimento é a principal fonte de alegria para Carolina e seus filhos e sua filha, o que marca o fim daquela época triste: "Agora com a fartura de comida os filhos estão enfastiados. Supernutridos [sic]. São mais barulhentos, mais dispostos. Tenho a impressão que estou despertando de um sonho, sonho que foi assim: cadeia, fome, enchente, brigas" (Jesus, 1961, p. 36). Toledo (2011) traz que é como se a escrita de Casa de Alvenaria acabasse se referindo a um tempo antigo, mas não tão distante, visto que as memórias dela aparentam estar a todo o momento dialogando com o presente e o passado, tal como nos mostra aqui: "Outro dia eu estava em São Paulo percorrendo a Avenida Tiradentes, fussando as latas de lixo. Chorando com fome" (Jesus, 1961, p. 93).

Enquanto critica o ambiente da favela pelos seus acontecimentos, ela também acaba criticando seu espaço atual, evidenciando, assim, uma crítica social (Silva, 2016) bem como a dificuldade em adaptar-se à convivência com pessoas de outra classe social. Frequentando espaços diferentes dos quais estava acostumada, a escritora ficava perplexa com o comportamento das mulheres de classe média alta: "Eu fiquei horrorizada porque as madames jogavam metade das comidas fora. E no preço que está os generos alimentícios!” (Jesus, 1961, p. 75). Essa era uma das atitudes que Carolina repudiava na conduta das pessoas que passou a conhecer. São esses universos que moldam a escrita de Carolina: de um lado o lugar que ela tanto quis sair por nunca ter se sentindo pertencente e do outro a sua ambiciosa e vivida casa de alvenaria, a qual também não se sente pertencente (Silva, 2016).

\section{Segunda pista: A escolarização como possibilidade de inserção no mundo.}

O desejo pelo conhecimento e sua imediata interdição foram por muito tempo características indivisíveis na vida do povo negro. Apesar de terem sido julgadas(os) incapazes de aprender e, em vários lugares do mundo, legalmente proibidos de ter acesso às instituições formais de ensino, as teóricas feministas Angela Davis (2016) e bell hooks (2013) asseveram que desde sempre essa população manifestou grande vontade de saber. Davis (2016) afirma que para a autoridade branca e seus princípios dominantes, a comunidade negra era incapaz de progressos racionais e 
intelectuais. Entretanto, analisa a autora, supondo que fossem realmente incapazes, teriam demonstrado tanto interesse pela aquisição de conhecimento? Faz todo sentido quando bell hooks (2013) destaca que as(os) negras(os) intelectuais representam perigo para a elite branca. E Carolina ilustra bem esse pensamento quando nos conta que "[...] os doutores de Coimbra diziam que quem deveria estudar eram os filhos da classe predominadora, e não os que deveriam ser predominados, que o amo e o servo não poderiam ter sapiência igual" (Jesus, 1977/2014, p. 39).

É importante ressaltar que o Brasil foi um dos países que, legalmente, proibiu a população negra de acessar as instituições formais de ensino, através de leis e constituições. Benedito José, o avô de Carolina, elucida essa questão ao destacar que "[...] na época que os seus filhos deveriam estudar não eram franqueadas as escolas para os negros", e complementa alertando às netas e netos: "Quando vocês entrarem nas escolas, estudem com devoção e esforcem-se para aprender" (Jesus, 1977/2014, p. 60). Mais tarde, quando acamado e perto de seu falecimento, a escritora relata que: "As pessoas que iam visitar o vovô saíam comentando: - Que homem inteligente. Se soubesse ler, seria o Sócrates africano [...]. Outros comentavam: - Foi crime não educá-lo. Este homem seria o Homem!" (Jesus, 1977/2014, p. 122).

Oficialmente, foi apenas em 1879, com a Reforma do Ensino Primário e Secundário de Leôncio Carvalho, que a população negra garantiu acesso às escolas públicas formais, quando se institui a obrigatoriedade do ensino para crianças dos sete aos quatorze anos e cai o veto que proibia o acesso de qualquer pessoa às instituições escolares. A partir daí algumas(uns) escravizadas(os) passam a frequentar escolas profissionalizantes e se tornam capacitadas(as) para instruir as(os) outras(os) nos espaços informais (Almeida, \& Sanchez, 2016). Porém, essa medida não foi suficiente para assegurar uma educação factual, visto que outros obstáculos começam a surgir para a população pobre do país, majoritariamente negra (Barros, 2005). A Reforma Rivadávia Corrêa, por exemplo, de 1911, exigia cobrança de taxas e estabelecia processos de avaliação para o ingresso nas escolas, organizando o impedimento das populações negras e de outros segmentos sociais mais vulneráveis (Garcia, 2007).

Ao visualizar este panorama e pensar sobre os dias atuais, percebemos que os propósitos do sistema educacional permanecem os mesmos: produzir seres disciplinados, alienados e acríticos (Souza; Ferreira \& Barros, 2009). A atual 
estratégia utilizada é o afastamento e inviabilização do acesso de grupos subalternizados às instituições educacionais, sobretudo da população negra. É nesse sentido que Carolina lamenta as circunstâncias que a fizeram não concluir seus estudos: "[...] Eu nada tenho que dizer da minha saudosa mãe. Ela era muito boa. Queria que eu estudasse para professora. Foi as contingências da vida que lhe impossibilitou concretizar o seu sonho" (Jesus, 1960, p. 49). A escritora, que estudou somente dois anos, uma vez que precisou migrar para outras cidades junto de seus familiares em busca de melhor condição de vida, nos apresenta exemplos reais de como esse desejo pelo conhecimento era intenso. Ela diz: "Foi com pesar que deixei a escola. Chorei porque faltavam dois anos para eu receber o meu diploma. Único meio foi resignarme, porque a decisão paterna vence" (Jesus, 1977/2014, p. 131).

Nesse caminho de atual admissão nas escolas, no final do século XIX, o povo negro precisou enfrentar inúmeras dificuldades para continuar realizando o grande desejo de estudar. Barros (2005) apresenta o racismo e a discriminação de classe como os principais obstáculos, enquanto que Patto (1992) corrobora afirmando que estas são problemáticas estruturantes das práticas e processos escolares, uma crise que a escola pública enfrenta desde muito tempo. Nesse sentido, com base em dados de 2010 do Ministério da Educação e da Saúde, Suleiman (2014) aponta a escola como um dos espaços sociais onde as crianças negras mais se deparam com situações de racismo e discriminação racial. Carolina relata o que via e ouvia na sua infância: "No ano de 1925, as escolas admitiam alunas negras. Mas quando as alunas negras voltavam das escolas, estavam chorando. Dizendo que não queriam voltar à escola porque os brancos falavam que os negros eram fedidos" (Jesus, 1977/2014, p. 42).

Experiências escolares como esta, afirma Cavalleiro (2005), provocam nos sujeitos negros uma série de problemas, como dificuldades no processo de aprendizagem; pouca ou nenhuma participação em sala de aula; ausência do reconhecimento de suas capacidades pessoais; recusa em ir à escola e, como resultado, a evasão. Este último aspecto, assim como a ausência da escolarização (sistematizada), torna-se um dos efeitos sociais mais devastadores da proibição do acesso da(o) negra(o) às escolas, visto que esta população experimenta até os dias de hoje o problema da evasão escolar contínua, a não admissão no ensino superior e a grande ocupação em cargos trabalhistas informais, precários e de baixa 
remuneração (Santos \& Scopinho, 2011). Carolina nos conta: "Os oito filhos do meu avô não sabiam ler. Trabalhavam nos labores rudimentares. O meu avô tinha desgosto porque seus filhos não aprenderam a ler" (Jesus,1977/2014, p. $60)$.

Diante do que foi exposto, acreditamos que a escola, como núcleo estruturante e formador de futuras(os) adultas(os), necessita urgentemente se integrar à luta antirracista. Como bem aponta Suleiman (2014), seria de grande relevância que as escolas formais públicas e privadas trabalhassem com mais responsabilidade a respeito da nossa história e do processo de formação do povo brasileiro, não mais sob a perspectiva branca eurocêntrica que dissemina (in)verdades inquestionáveis e universais.

\section{Terceira pista: Narrativa testemunhal como instrumento de resistência.}

Carolina Maria de Jesus se coloca em sua letra e afirma seu eu através de seus diários: "O meu registro geral é 845.936" (Jesus, 1960, p. 16). Entre outras características, a autora escreve em primeira pessoa do singular e apresenta uma garantia sobre a verdade da história relatada, elementos comuns de escritas pessoais de um modo geral (Alós, 2009;
Sousa, 2012), narrativas que englobam gêneros textuais construídos pela elaboração e organização de si, conforme Perpétua (2014). Porém, ao falar "eu”, seu texto expande-se e alcança o "nós", permitindo-nos pensar como pista os seus diários enquanto instrumento político de resistência para grupos marginalizados, através do conceito de narrativa testemunhal.

A princípio, refletimos sobre a Literatura para além de uma dimensão puramente abstrata. Através de Sousa (2012) compreendemo-la enquanto instituição e campo político, marcado por relações de poder. Trata-se de um veículo capaz de produzir e propagar discursos, sendo ainda espaço de expressão privilegiado e dominado por um grupo seleto que difunde discursos hegemônicos, representados por seus próprios interesses. É um meio de enunciação e representação de sujeitos, grupos e sociedades. Carolina (1961, p. 17) enuncia: "[...] agora eu falo e sou ouvida. Não sou mais a negra suja da favela". Coimbra e Leitão (2003) discorrem sobre como o sistema capitalista produz dispositivos de desigualdades que estabelecem e naturalizam dois territórios: o do saber-poder e o do não-saber. $\mathrm{O}$ primeiro se trata de uma posição detentora de conhecimento, de verdade, autoridade e legitimação de modos de ser; já o segundo 
é um lugar excluído, deslegitimado, segregado e marginalizado.

Escrever a História e criar verdades está nas mãos de poucos. Para Alós (2009) e Magnabosco (1999), a Literatura e a História do século XIX e meados do século XX estão pautadas por uma base masculina. Porém, a partir dos anos de 1960 e 1970, surge em ascensão um novo discurso narrativo de resistência baseado na voz subalterna (Perpétua, 2013). Segundo Magnabosco (1999), surgem com função política de denunciar opressões e marginalizações praticadas aos subalternos de linguagem, grupos que não se enunciam na história oficial hegemônica; são considerados como afronta por se opor à linguagem culta, vistos como subversivos, desviantes e marginais. Esse novo cenário permite o nascimento de um novo sujeito narrativo que se escreve e inscreve por outra posição (Perpétua, 2013).

Diante de um cenário histórico e social de extrema violência e resistência às três ditaduras que se expandem na América Latina, a narrativa testemunhal passa a ser marcada por extremo teor político, dando surgimento ao testemonio. Esse surge a partir da necessidade de representação e expressão de sujeitos subalternos diante da opressão sofrida em seu respectivo contexto; torna-se porta-voz de grupos silenciados, marginalizados e oprimidos, conforme Alós (2009) e Seligmann-Silva (2008). Segundo este último, a escrita se torna uma via até mesmo de sobrevivência, um modo de elaborar o teor insuportável da experiência. Ainda que cada testemunho seja singular, trata-se de uma narrativa que rompe com a escrita puramente individual (elemento mais próximo da autobiografia) e elabora uma autoria coletiva. No "eu" que fala há a representação de uma coletividade (Alós, 2009; Sousa, 2012). O testemonio pode se manifestar em diferentes formatos e se caracteriza por seu teor político, representativo, visibilizando uma cultura desautorizada e desprestigiada (Alós, 2009). Por isso pensamos os diários carolinianos a partir desse conceito, afinal sua escrita está imersa em um contexto político de opressão, em tom de denúncias e de autorrepresentação.

$$
\text { Conforme Sousa (2012), a }
$$
representação artística de qualquer indivíduo está atravessada, ainda que inconscientemente, por seu papel social e político, pelo seu ser no mundo e pela sua história. Apesar de Carolina não se nomear diretamente porta-voz do grupo e narrar sobre sua dimensão pessoal, suas obras se expandem para uma coletividade que a transborda durante todo o discurso (Fernandez, 2008). Sua escrita subalterna se torna um instrumento político por si, fornecendo visibilidade e representação a 
uma cultura desautorizada (Alós, 2009). Dessa forma, analisamos como a escrita diarística e a narrativa testemunhal podem ser uma ferramenta de intervenção e transformação social para grupos subalternos, excluídos do lugar discursivo privilegiado. Carolina utilizou desses modelos de narrativas como modo de sobrevivência, de elaboração de si e do mundo: "[...] tem pessoas que quando estão nervosas xingam ou pensam na morte como solução. Eu escrevia o meu diário" (Jesus, 1961, p. 22). Sua forma de construir o texto resiste ao modelo hegemônico e canônico, desestabiliza e reorganiza o sistema literário padrão. A autora utiliza o campo da literatura para guerrear no campo político, escancarando para o mundo as verdadeiras facetas da favela, contrastadas ao projeto político que encenava o desenvolvimento, vigente em tal período: "Duro é o pão que nós comemos. Dura é a cama que dormimos. Dura é a vida do favelado" (Jesus, 1960, p. 37).

Enquanto a norma exclui e discrimina $\mathrm{a}(\mathrm{o})$ subalterna(o), Carolina eleva a voz marginalizada para o campo dominante, elabora algo novo, único, rejeitado inicialmente por uma crítica que visa estabelecer a ordem dominante, tão distante da norma que causa estranhamento (Sousa, 2012). Ressaltamos que há sujeitos sociais, como acadêmicas(os) e jornalistas, que detém o poder de definir e legitimar o valor literário e estético de produções textuais (Coronel, 2014). O próprio conceito de "qualidade estética" implica questões políticas e ideológicas, como noções hegemônicas de beleza e harmonia, porém a exigência para uma estética padronizada pode não coincidir com as vivências de grupos subalternos. Dessa forma, o cânone literário hierarquiza e define o que é ou não literatura: há a literatura maior, com gêneros valorizados e reconhecidos (como o romance e a poesia épica) e os gêneros menores, marginalizados no cenário literário, posicionado abaixo do que seria a "arte verdadeira" (Alós, 2009). As narrativas de si são situadas enquanto literatura menor, quando não desconsideradas totalmente em seu teor artístico, tal como aconteceu com a escrita caroliniana (Alós, 2009; Coronel, 2014; Perpétua, 2014; Sousa, 2012).

Ao nos depararmos com seus diários, não é difícil supor que a autora tinha ciência do poder de sua escrita. Revela-nos que sua força está nas palavras: “[...] Não tenho força física, mas as minhas palavras ferem mais do que espada. E as feridas são incicatrisaveis" (Jesus, 1960, p. 43). No movimento de narrar sobre si, representa uma população que não tem letra no discurso hegemônico: discursa 
sobre o que é ser mulher, negra, moradora da favela e mãe solteira; sobre a miséria, a fome e tantos outros temas.

\section{Quarta pista: Um olhar sobre a branquitude feminina.}

Carolina, em seu romance Pedaços da Fome (1963), tece entrelaçamentos entre narrativa e experiência ao trabalhar a fome, o gênero, a raça e as desigualdades sociais, sobretudo no que se refere à luta de classes. As(os) personagens que compõem o enredo são carregadas(os) de estereótipos vigentes à época, especialmente ao retratar a figura da protagonista Maria Clara, jovem branca e rica do interior paulista, filha do Coronel Fagundes e Dona Virginia. O livro nos permite analisar a construção de uma protagonista branca criada a partir do olhar de uma mulher negra, compreendendo assim que o escrito abarca uma história sobre raça, especialmente no que se refere aos enlaces de uma branquitude feminina.

Os elementos que compõem e configuram esses enlaces são vistos no começo da obra. A princípio com Dona Virginia, sendo descrita como uma dona de casa resiliente, paciente e submissa ao seu marido, que diz "Eu ainda gosto de você, por que é boa dona de casa, boa esposa e boa enfermeira, quando estou doente cuida de tudo com desvelo "(Jesus, 1963, p. 18). Essa noção de feminilidade, que define o papel das mulheres como mães, parceiras, donas de casa amáveis, era destinada apenas às mulheres brancas, pois os corpos negros eram destituídos de humanidade. Desse modo, o espaço destinado à mulher negra, como Carolina, no ambiente domiciliar era, exclusivamente, o de empregadas domésticas (Davis, 2016).

Coronel Fagundes, personificação do patriarcado, o homem que possui o poder sobre o corpo e os comportamentos femininos, sejam os da mulher ou os da filha, afirma que "[...] cabe ao homem introduzir e guiar a mulher num núcleo culto, para que ela possa se tornar a sua companheira em todos os campos" (Jesus, 1963, p.17). Em seguida, relata para a esposa: "Quando o teu pai apresentou-me tuas irmãs para eu escolher-lhe a minha companheira para acompanhar-me nos alpes da vida, gostei de você [...] era miudinha, parecia uma boneca" (Jesus, 1963, p. 18). Nota-se aqui a configuração do sistema "troca de mulheres" (Rubin, 1975/1993, p. 10), no qual as mulheres brancas são transacionadas através do casamento.

Nas páginas iniciais, vemos a aspiração de Maria Clara em “[...] ser amada, ser venerada. Ocupar um lugar de destaque no coração de um homem. 
Receber seus olhares de ternuras. Os seus afagos" (Jesus, 1963, p.23-24). Seus sonhos foram construídos pela ideia de um amor romântico que lhe traria a felicidade. Adiante, ela conhece Paulo Lemes, que se apresenta como "doutor dentista" (Jesus, 1963, p. 27) da capital paulista e, a partir daí, iniciam uma relação amorosa. Quando os rumores da relação chegam aos ouvidos do Coronel, ambos são forçados a se casarem para manter a reputação da moça e honrar o nome da família. Sua mãe mostrase contrária ao matrimônio, mas tem sua oposição anulada, já que, como aponta Rubin (1975/1993), as mulheres se encontram disponíveis aos homens como uma propriedade. Elas não possuem nem a si mesmas, que dirá a outra mulher. Maria Clara é dada em casamento e a responsabilidade sobre seu corpo é passada do pai ao marido. Segundo Rubin (1975/1993), os casamentos consistem em uma troca de presentes, na qual os corpos femininos são os produtos e os homens são os companheiros nessa troca. As mulheres negras encontravam-se fora desse contrato social, visto que a escravidão que as(os) negras(os) foram submetidas(os) as(os) retiravam desse sistema (Haraway, 2004; Davis, 2016).

Carolina constrói uma protagonista dando destaque a sua cor, já que apenas a raça de Maria Clara é identifica no enredo.
De acordo com Pureza (2017), a cor de Maria Clara confere a ela um local de poder e beleza, reafirmado pela(o) narradora(r) no decorrer da história: "Paulo fitou a esposa com seus cabelos revoltos. Bela como a Vênus. Aquela pele nívea e acetinada" (Jesus, 1963, p.77), em seu nome anunciava sua raça o qual Paulo define como "[...] branco, puro, exclarecido" (Jesus, 1963, p. 29). A mulher branca, em nossa sociedade estruturalmente racista, continua sendo a representação da beleza e pureza, enquanto a mulher negra se constitui como sua oponente.

Após o casamento, Maria Clara vai para a capital com Paulo. Lá ela descobre que irá residir em um cortiço, percebendo que seu marido mentiu sobre sua formação profissional e classe social. A jovem sofre a desilusão com a cidade grande, retirada do conforto da casa dos pais para vivenciar a pobreza e as agruras da vida. A obra nos mostra como as condições socioeconômicas nos coloca em lugares específicos: da fazenda ao cortiço, do cortiço à favela, da favela à fazenda; e como cada espaço ocupado reservava um lugar social de riqueza, pobreza ou miserabilidade, trazendo a desigualdade social agravante em nosso país. Para Maria Clara, o casamento foi oposto às suas idealizações. Em virtude disso, ela afirma 
por vezes ser "escrava" (Jesus, 1960, p. 189) da fome e do marido. Para Davis (2016), a metáfora da escravidão é comum às mulheres brancas numa tentativa de expressar as opressões sofridas, sendo associada frequentemente às experiências domésticas matrimoniais, visto que elas tornam as mulheres brancas propriedades de seus maridos, dependentes financeira e emocionalmente (Davis, 2016). Maria Clara, que sempre ouviu de sua mãe que a mulher deve obediência e submissão ao marido, encontra-se presa ao casamento.

$O$ gênero se torna um dos eixos principais da história a partir do casamento da protagonista. De acordo com Rubin (1975/1993, p. 11), o gênero é a “[...] divisão dos sexos socialmente imposta [...] e produto das relações sociais de sexualidade". Desse modo, homens e mulheres são constituídos como incompletos, tornando-se completos através do casamento heterossexual. O matrimônio de Maria Clara com Paulo, um homem que tem repulsa ao trabalho e conformado com sua situação social, faz com que a jovem se torne a provedora da casa. Todavia, a execução da função de prover o lar, tipicamente direcionada ao homem, não é suficiente para que a jovem protagonista alcance sua independência, uma vez que, como aponta Pelúcio (2017), nem tudo pode ser explicado tão somente a partir do gênero.

Carolina constrói a personagem de Maria Clara como uma mulher completamente desprovida de autossuficiência. No sentido oposto, Davis (2016) aponta que as mulheres negras desenvolvem um espírito de independência e de autossuficiência pela necessidade de sobrevivência. O corpo da mulher negra é historicamente hiperssexualizado, objeto de servidão, mão de obra barata. Esse corpo não poderia jamais ser considerado como "frágil" nem tampouco "feminino" e, assim, as mulheres negras não poderiam ser "donas de casa" (Davis, 2016). Presa em um casamento com um "malandro", Maria Clara se torna provedora da família e mãe solteira de seis filhos. Carolina traz em seu romance a denúncia sobre uma realidade atual, o abandono parental, vivenciado por Maria Clara e seus filhos mesmo com a figura masculina ao lado. Segundo Haraway (2004), o conceito ocidental de gênero determina que a maternidade é biologicamente natural e a paternidade é inferida. Percebe-se o caráter obrigatório da maternidade, bem como a função de cuidadora destinada à mulher.

Desta forma, centralidade no marcador gênero não produz o apagamento dos outros eixos que constituem a protagonista, ao contrário, nos permite 
traçar aproximações com a autora e compreender que o "ser mulher" não prediz um único lugar social, tampouco uma única forma de ser, visto que a constituição desse "ser mulher" é atravessado por outros marcadores. Assim, como discorre Mello e Gonçalves (2012), o indivíduo não pode ser dividido em situações específicas e, do mesmo modo, as opressões não devem ser analisadas ou combatidas separadamente, elas coexistem e se reforçam mutuamente. Isso nos permite perceber as diferentes nuances presentes nessas formas de opressões sem necessariamente haver uma sobreposição entre elas, de forma que, a partir da leitura de Pedaços da Fome, podemos observar como os marcadores sociais de mulherbranca-interiorana-heterossexual-casada constitui a figura de Maria Clara, assim como sua visão de mundo.

\section{Quinta pista: As relações étnico-raciais e o ser negra(o) no Brasil.}

Em seus escritos, Carolina abarca diferentes dimensões existentes nas relações étnico-raciais. Ao adentrar nessa pista, é possível visualizar as marcas subjetivas que são resultantes das desigualdades dessas relações, em que é produzida alteridade, sendo possível observar quando a autora afirma que "eu sabia que era negra por causa dos meninos brancos. Quando brigavam comigo diziam: Negrinha! Negrinha fedida!” (Jesus, 1977/2014, p. 94). De acordo com Kilomba (2019, p.38), “a Negritude serve como forma primária de alteridade, pela qual a branquitude é construída. O 'Outro' não é outro per se; ela(e) torna-se tal através de um processo de absoluta negação". Além disso, as características que o sujeito branco não quer reconhecer em si são projetadas nas(aos) negras(os) como estratégia para ocultar o seu projeto de dominação, e, assim, "manter e legitimar estruturas violentas" de poder (Kilomba, 2019, p.34).Para não trazer à tona verdades indesejáveis e revelar os privilégios $\mathrm{da}(\mathrm{o})$ branca(o), há uma tentativa de silenciar a população negra e seus conhecimentos (Kilomba, 2019). Evidencia-se, assim, a importância dos conhecimentos transmitidos por Carolina, que é perspicaz a essa postura da(o) branca(o) em colocar a(o) negra(o) como alteridade.

O lugar privilegiado ocupado pelo sujeito branco é outra dimensão trazida pela escritora. Há um entrelace entre a branquitude e os privilégios que é sustentado como um direito natural, legitimando as desigualdades através de uma suposta essência intrínsecaas(aos) brancas(os) que confere a elas(es) 
superioridade intelectuais e morais em comparação a outros sujeitos (Carneiro, 2011; Schucman, 2014). Como consequência, percebe-se a "necessidade de adjetivar racialmente" os sujeitos negros "para expressar o desprezo pela negritude" a fim de que a(o) branca(o) não seja desvalorizada(o) (Carneiro, 2011, p. 125). "Os brancos falavam que os negros eram fedidos" (Jesus, 1977/2014, p. 43) e "quando alguém ia me xingar era: Negrinha!" são relatos da escritora que denotam esse processo. Quando se trata de sujeitos negros, há o discurso: "Você é juíza mas...é negra. Você é...mas é negro!" (Carneiro, 2011, p. 125). Carolina teve seus escritos renegados repetidas vezes pelo discurso de "pena que você é preta" (Jesus,1960, p. 58). A escritora questionou essa inferiorização vista em suas relações sociais: "que superioridade apresenta o branco? se o negro bebe pinga, o branco bebe. A enfermidade que atinge o preto, atinge o branco. Se o branco sente fome, o negro também" (Jesus, 1960, p. 58). Dessa forma, "se os pretos tivessem chegado ao mundo depois dos brancos, aí os brancos podiam protestar com razão. Mas, nem o branco nem o preto conhece a sua origem" (Jesus, 1960, p. 58), sendo assim, concluía que "Deus criou todas as raças na mesma época. Se criasse os negros depois dos brancos, aí os brancos podia revoltar-se" (Jesus, 1960, p. 108).

O racismo é uma importante via para compreender a internalização da inferioridade, se apresentando por no mínimo duas faces: racismo aberto e racismo fechado. Sobre o primeiro, há um desprezo pela ideia da miscigenação já que as(os) brancas(os) queriam manter sua "pureza" e "superioridade". Por sua vez, o racismo fechado ou disfarçado produz maior alienação das(os) subalternizadas(os), pois é sustentado pela ideia de miscigenação e democracia racial, atribuindo $\mathrm{o}$ racismo como inexistente(Gonzalez, 1988). Nesse último, é possível analisar de onde parte o questionamento de Carolina sobre "por que será que os mulatos e os brancos negavam os negros?” (Jesus, 1977/2014, p.74). Essa negação era contraditória para a escritora, já que "[...] o branco não aceita o mulato como branco. Houve até um projeto dizendo que se o mulato tivesse o cabelo liso era considerado branco, se o cabelo fosse crespo então o mulato era considerado negro" (Jesus, 1977/2014, p.74). O termo"mulata(o)" é pejorativo, originado da palavra portuguesa "mula", que significa o resultado do acasalamento entre uma jumenta/égua e um cavalo. Isso infere, sobretudo, na discussão sobre a inferiorização do sujeito negro por parte de 
um discurso de embranquecimento (Kilomba, 2019). O termo trazido por Carolina contribui para pensar sobre o racismo disfarçado e os silenciamentos do cotidiano que reforçam a subordinação dos sujeitos negros.

O pensamento da escritora também se conecta ao debate sobre os preceitos eugenistas e higienistas (Werneck, 2004; Carneiro, 2011): "o branco criou a alta sociedade, lá não existia os negros" (Jesus, 1960, p.64). No início do século XX, tinhase como intuito a eliminação dos sujeitos considerados como antagônicos à modernização da cidade e que apresentavam riscos a comodidade da elite (Werneck, 2004). Assim, a população negra é deslocada aos espaços periféricos e são atribuídos estereótipos de marginalidade (Gonzalez, 1982), trazido por Jesus (1960, p. 73) ao relatar que "quando alguém nos insulta é só falar que é da favela e pronto. Nos deixa em paz. Percebi que nós da favela somos temido". Como íntima relação a isso, "por aí que se entende porque o outro lugar natural do negro sejam as prisões” (Gonzalez, 1982). Como resultado dessa visão, têm-se a massiva intervenção policial, que se caracteriza como uma sistemática repressão que tem sustentação no racismo (Gonzalez, 1982). De acordo com Jesus (1977/2014, p.39) era nítida a

culpabilidade aos negros em episódios de violência, visto que "quando ocorria um crime ou roubo na cidade, os pretos eram os suspeitos. Os policiais prendiam. Quantas vezes eu ouvia os maiorais dizendo: Negros ladrões, negros ordinários!" e "[...] aquele negro, sem nunca ter roubado, era um ladrão".

Por fim, compreende-se que o lugar da(o) negra(o) na sociedade não diz respeito somente ao lugar físico, mas também social, cultural, político e simbólico. A reflexão proposta por Kilomba (2016) torna possível abarcar essas dimensões quando afirma que através do sistema racista os corpos negros nunca pertencem, pois são vistos como indignos e abjetos, enquanto os corpos dos sujeitos brancos são sempre aceitos. Assim, são demarcações de espaços que demonstram a dinâmica racista que torna as(os) negras(os) sempre fora do lugar e a impossibilidade de alcançá-lo. Porém, há movimentos de resistência, como trazido por Carneiro (2011, p.126) quando ela diz que "os poucos espaços se constituem em instância de afirmação de humanidade e igualdade sistematicamente negadas pelo racismo".

\section{Considerações Finais}


Ao discutir a obra de Carolina, Silva (2019), chama a atenção para nos atentarmos à lógica do “des(p)ejo das palavras", levando em consideração que vivemos um momento político de apagamento das vozes - de negras e negros, população LGBT, mulheres, ativistas e artistas. Os últimos meses tiveram como acréscimo a propagação da ideia de que somente uma "arte conservadora", temperada a nada sutis ideais totalitários, salvariam a população brasileira, devolvendo-lhe a ordem, a família intocada, a homogeneidade tão costumeira. Esta arte conservadora que prega o atual governo ultradireitista seria responsável em unificar a nação, tornandoa aquilo que sempre foi: uma nação que volta as costas para as diferenças, que as trancafia em quartos de despejos hermeticamente fechados. Neste sentido, ao incitarem tão ferrenhamente a ideia de que é por meio da arte e da cultura que uma população se forma (e se transforma), eles acabam por reconhecer a importância dessa esfera no cotidiano das pessoas. Stuart Hall (1997, p. 18) já dizia: "Se a cultura, de fato, regula nossas práticas sociais a cada passo, então, aqueles que precisam ou desejam influenciar o que ocorre no mundo ou o modo como as coisas são feitas necessitarão - a grosso modo - de alguma forma ter a 'cultura' em suas mãos, para moldá-la e regulá-la de algum modo ou em certo grau".

\section{Referências}

Almeida, M. A. B.\& Sanchez, L. (2016). Os negros na legislação educacional e educação formal no Brasil. Revista Eletrônica de Educação, 10(2), 234246. doi: 10.14244/198271991459

Alós, A. P. (2009). Literatura e intervenção política na América Latina: relendo Rigoberta Menchú e Carolina Maria de Jesus. Cadernos de Letras da UFF - Dossiê: Diálogos Interamericanos, 38, 139162. Recuperado de http://www.cadernosdeletras.uff.br/jo omla/images/stories/edicoes/38/artig o8.pdf

Barros, S. A. P. (2005). Discutindo a escolarização da população negra em São Paulo entre o final do século XIX e início do XX. InJ. Romão (Org.). História da educação dos negros e outras histórias(pp. 7992).Brasília/DF: Ministério da Educação.

Carneiro, S. (2011). Racismo, sexismo e desigualdade no Brasil. São Paulo: Selo Negro.

Cavalleiro, E. S. (2005). Apresentação. InJ. Romão (Org.). História da educação dos negros e outras histórias(pp. 9-10).Brasília/DF: Ministério da Educação.

Coimbra, C.\& Leitão, M. B. S. (2003). Das essências às multiplicidades: especialismo psi e produções de subjetividades. Psicologia \& Sociedade, 15(2), 6-17. Doi: http://dx.doi.org/10.1590/S010271822003000200002 
Coronel, L. P (2014). A censura ao direito de sonhar em Quarto de despejo, de Carolina Maria de Jesus. Estudos de literatura brasileira contemporânea, 44, 271-288. Doi: http://dx.doi.org/10.1590/231640184412

Davis, A. (2016). Mulheres, raça $e$ classe. (H. R. Candiani, Trad.). São Paulo: Boitempo.

Fernandez, R. A. (2008). Percursos de uma poética de resíduos na obra de Carolina Maria de Jesus. ItineráriosRevista de Literatura, 27, 125146. Recuperado de https://periodicos.fclar.unesp.br/itine rarios/article/view/1131

Fernandez, R. A. (2015). Gestos e genealogia: diferentes estados de um texto. In R. A. Fernandez. Processo criativo nos manuscritos do espólio Literário de Carolina Maria de Jesus (pp. 85 - 133).(Tese de Doutorado). Instituto de Estudos da Linguagem, Universidade Estadual de Campinas, Campinas.

Garcia, R. C. (2007). Marcos institucionais. In R. C. Garcia (Org.). Identidade fragmentada: um estudo sobre a história do negro na educação brasileira: 1993-2005(pp. 33-38).Brasília: Instituto Nacional de Estudos e Pesquisas Educacionais Anísio Teixeira.

Gonzalez, L. (1982). O movimento negro na última década. In L. Gonzalez \& C. A. Hasenbalg. Lugar de negro (pp. 9-66). Rio de Janeiro: Marco zero.

Gonzalez, L. (1988). A categoria políticocultural de amefricanidade. Tempo Brasileiro, Rio de Janeiro, 92(93), 69-82.
Recuperado dehttps://negrasoulblog.files.wordpre ss.com/2016/04/a-categoriapolc3adtico-cultural-deamefricanidade-lelia-gonzales1.pdf

Hall, S. (1997). A centralidade da cultura: notas sobre as revoluções culturais do nosso tempo. Educação \& realidade, 22(2), 15-46. Recuperado dehttps://www.seer.ufrgs.br/educaca oerealidade/article/view/71361

Hall, S. (2016). Cultura e representação. Rio de Janeiro, PUC-Rio: Apicuri.

Haraway, D. (2004). "Gênero" para um dicionário marxista: a política sexual de uma palavra. Cadernos Pagu, Campinas, 22, 201-242. Doi: http://dx.doi.org/10.1590/S0104$\underline{83332004000100009}$

bell hooks. (2013). Introdução.Inbell hooksl (Org.). Ensinando a Transgredir: A educação como prática da liberdade(pp. 09 - 24), M. B. Copolla, Trad.). São Paulo: Editora WMF Martins Fontes.

Jesus, C. M. (1960). Quarto de Despejo:diário de uma favelada. São Paulo: Editora Francisco Alves.

Jesus, C. M. (1961). Casa de Alvenaria: diário de uma ex-favelada. São Paulo: Livraria Francisco Alves (Editora Paulo de Azevedo Ltda).

Jesus, C. M. (1963). Pedaços da Fome. São Paulo, Editora Aquila Ltda.

Jesus, C. M. (2014). Diário de Bitita. São Paulo: SESI-SP editora. (Original publicado em 1977).

Kilomba, G. (2010). A máscara. Cadernos de Literatura em Tradução, 16, 171-180. Recuperado de 
https://www.revistas.usp.br/clt/article /viewFile/115286/112968

Kilomba, G. (2019). Memórias da plantação: episódios de racismo cotidiano. Rio de Janeiro: Editora Cobogó.

Magnabosco, M. M. (1999). Testemunhos narrativos femininos na América Latina: Uma articulação interdisciplinar. Em Tese, 3, 51-58. Doi:

http://dx.doi.org/10.17851/19820739.3.0.51-58

Mello, L. \& Gonçalves, E. (2012). Diferença e interseccionalidade: notas para pensar práticas em saúde. Revista Cronos, 11(2). Recuperado de

https://periodicos.ufrn.br/cronos/artic le/view/2157

Miranda, F. R. (2013). A “escrita de si”. InF. R. Miranda, Os caminhos literários de Carolina Maria de Jesus: experiência marginal $e$ construção estética(pp. 117136).(Dissertação de Mestrado). Faculdade de Filosofia, Letras e Ciências Humanas, Universidade de São Paulo, São Paulo.

Oliveira, E.C.S. (2017). "Uma monstra perigosa": pistas de Carolina Maria de Jesus para a intervenção psicossocial. Estudos de Psicologia, 22, 378-388. Recuperado de http://pepsic.bvsalud.org/scielo.php? script=sci_arttext\&pid=S1413294X2 017000400005\&lng=pt\&nrm=iso\&tl $\mathrm{ng}=\mathrm{pt}$

Oliveira, E.C.S; Bleinroth, M. L. M.; Santos Júnior, J. C.; Silva, L. T. dos S.; Melo, W. da C. (2018). "6 de frente, 12 de fundo": relações entre processos de subjetivação e moradia na obra de Carolina Maria de Jesus.
In O. C. Mattioli; M. de F. Araújo. (Org.). Violência e relações de gênero: dez anos de publicações e pesquisas (pp. 193-207). 1ed.Curitiba: CRV, v. 1.

Oliveira, E.C.S. (no prelo). O pensamento de fronteira de Carolina Maria de Jesus. Psicologia: Ciência e Profissão.

Patto, M. H. S. (1992). A família pobre e a escola pública: anotações sobre um desencontro. Psicologia USP, 3(1-2), 107-121. Doi https://doi.org/10.1590/S1678$\underline{51771992000100011}$

Pelúcio, L. (2012). Subalterno quem, cara pálida? Apontamentos às margens sobre pós-colonialismos, feminismos e estudos queer. Contemporânea Revista de Sociologia da UFSCar. São Carlos, 2(2), 395418. Recuperado de http://www.contemporanea.ufscar.br/ index.php/contemporanea/article/vie $\mathrm{w} / 89 / 54$

Perpétua, E. D. (2013). Experiência estética e mídia impressa: o caso Carolina de Jesus.Anais do SILEL, Uberlândia: EDUFU, 3(1), 1-14 Recuperado dehttp://www.ileel.ufu.br/anaisdosile 1/wpcontent/uploads/2014/04/sile12013_3 106.pdf

Perpétua, E. D. (2014). A proposta estética em Quarto de despejo, de Carolina de Jesus. Scripta, 18(35), 255-266.

DOI: https://doi.org/10.5752/P.2358$\underline{3428.2014 \mathrm{v} 18 \mathrm{n} 35 \mathrm{p} 255}$

Pureza, F. C. (2017). Representações da fome: carestia e racialização na obra Pedaços da fome, de Carolina Maria 
de Jesus. Revista do Instituto de Estudos Brasileiros, (66), 52-68. Doi: http://dx.doi.org/10.11606/issn.2316$\underline{\text { 901x.v0i66p52-68 }}$

Rubin, G. (1993) Tráfico de mulheres:notas sobre a "economia política" do sexo. Tradução SOS Corpo. (Original publicado em 1975).

Santos, E. F.\& Scopinho, R. A. (2011). Fora do jogo?: Jovens negros no mercado de trabalho. Arquivos Brasileiros de Psicologia, 63, 2637.Recuperado de http://pepsic.bvsalud.org/scielo.php? pid=S180952672011000300004\&scr $\mathrm{ipt}=\mathrm{sci}$ abstract\&tlng=en

Schucman, L. V. (2014). Sim, nós somos racistas: estudo psicossocial da branquitude paulistana.Psicol. Soc., Belo Horizonte, 26(1), 83-94. Doi: http://dx.doi.org/10.1590/S010271822014000100010

Seligmann-silva, M. (2008). Narrar o trauma - A questão dos testemunhos de catástrofes históricas. Psicologia clínica, 20(1), 65 - 82. Doi: http://dx.doi.org/10.1590/S010356652008000100005.

Silva, E. C. (2016). A violência social em Casa de Alvenaria. InE. C. Silva. A violência social brasileira na obra de Carolina Maria de Jesus(pp. 7991).(Tese de Doutorado). Ciências Sociais - FCLAR, Universidade Estadual Paulista "Júlio de Mesquita Filho", Araraquara.

Silva, R. G. T. (2019). Des(p)ejo das palavras: relendo os primeiros diários de Carolina Maria de Jesus. Revista Estudos Feministas, 27(2), 1 13.Doi: http://dx.doi.org/10.1590/1806-95842019v27n254825

Sousa, G. H. (2012). Carolina Maria de Jesus: o estranho diário da escritora vira lata. Editora Horizonte.

Souza, P. R, Ferreira, M. M. M \& Barros, M. S. F. (2009). História da criação da escola pública como instrumento da formação da educação burguesa. In Congresso Nacional de Educação (EDUCERE).

Souza, A. A. (2016).Escrevendo na "sala de visita". InA. A. Souza. Do Quarto de Despejo à Sala de Visita: experiência e narrativa nos diários de Carolina Maria de Jesus (19551961) (pp. 72- 104).(Dissertação de Mestrado). Programa de PósGraduação em História, Universidade Federal da Paraíba, João Pessoa.

Spivak, G.C. (2010). Pode o subalterno falar? Belo Horizonte: UFMG Editora.

Suleiman, B. B. (2014). Psicologia e Ensino das Relações Étnico-Raciais: uma experiência na formação de professores. Psicologia Escolar $e$ Educacional, 18(2), 369-372. Doi: http://dx.doi.org/10.1590/21753539/2014/0182809

Toledo, C. V. S. (2011). O segundo diário: Casa de alvenaria. In C. V. S. Toledo. $O$ estudo da escrita de si nos diários de Carolina Maria de Jesus:a célebre desconhecida da literatura brasileira(pp. 5588).(Dissertaçãode Mestrado). Programa de Pós-Graduação em Letras, Pontifícia Universidade Católica do Rio Grande do Sul, Porto Alegre. 
Werneck, J. P. (2004). O belo ou o puro? Racismo, eugenia e novas (bio)tecnologias.. InA. A. Rotania; J. P. Werneck (Org.).Sob o Signo das Bios - vozes críticas da sociedade civil (pp. 49-63). 1ed. Rio de Janeiro: E-papers serviços Editoriais.

Érika Oliveira possui graduação em Formação de Psicólogo(a) pela Universidade Estadual Paulista Júlio de Mesquita Filho (1997). Atualmente é Professora Adjunta no Instituto de Psicologia da Universidade Federal de Alagoas e Professora Permanente no Programa de PósGraduação

em Psicologia da UFAL. Trabalha na área de Psicologia Social.

E-mail: erika.oliveira@ip.ufal.br

ORCID: http://orcid.org/0000-0003-4877$\underline{0971}$

Maria Laura Medeiros Bleinroth é mestranda em Psicologia pela Universidade

Federal de Alagoas, na linha de pesquisa Subjetividades, Políticas e Processos Psicossociais. Graduada em Psicologia pela Universidade Federal de Alagoas. Realiza pesquisas na área da Psicologia Social com ênfase em gênero, envelhecimento e educação.

E-mail: laurableinroth@gmail.com ORCID:https://orcid.org/0000-0002-1143$\underline{9196}$

Yasmin Maciane da Silva é graduanda em Psicologia pela Universidade Federal de Alagoas. Realiza pesquisas na área da Psicologia Social com ênfase em discussões sobre gênero, democracia, relações étnico-raciais, política e religião.

E-mail: macianeyasmin@gmail.com ORCID:https://orcid.org/0000-0002-3386$\underline{0360}$
Rayanne Caroline da Silva Amorim é psicóloga formada pela Universidade Federal de Alagoas - UFAL. Atua como Psicóloga Clínica em Maceió - Alagoas.

E-mail: rayanne.caroline_@hotmail.com ORCID:https://orcid.org/0000-0001-7565$\underline{6256}$

\section{José Cícero dos Santos Júnior é graduando em Psicologia pela Universidade}

Federal de Alagoas. Foi bolsista Cnpq no Programa Institucional de Bolsas de Iniciação Científica (PIBIC) enquanto realizava a pesquisa que resultou no presente artigo.

E-mail: junior.santos-@ hotmail.com

ORCID:https://orcid.org/0000-0002-6667$\underline{5428}$

Willamys da Costa Melo é graduando em Psicologia pela Universidade Federal de Alagoas. Realiza pesquisas na área da Psicologia Social sobre relações étnico-raciais, gênero e sexualidade e decolonialidade.

E-mail: willamys.costa@gmail.com

ORCID:https://orcid.org/0000-0001-7249$\underline{5653}$

Enviado em: 28/02/20- Aceito em: 09/04/20 